\title{
Ethical Standpoints in Relation to New Technologies (Neo-Technologies): Classification Plan, Miscommunication, and Perspectives
}

\author{
Bernard Claverie \\ Bordeaux University
}

The moral debate on convergent technologies, or neo-technologies, get a critical place both in the scientific literature and the public debate. Each one goes there from his own positions, by refuting those of the others. The conflict opposes supporters of different ethical positions, and it is difficult to navigate this debate on the usefulness, acceptability, or tolerance for the development of converging technologies. These NBIC technologies are judged according to moral "compartments" which involve both the hopes of humanity and fears which are the source of much resistance. These positions are in reference to moral bases developed and promoted by experts, users, or citizens confronted with the exponential development of these NBIC technologies.

Moral positions can be described in four trends: rejection, regulation, letting it happen, or encouraging the development. They are themselves modulated by the ethical value that these experts, users, or citizens attach to the real or fantasized issues of the fields of application: health, nature and environment, nurture and civilization, economic development.

Keywords: technology, biotechnology, information and communication technology, ethics, morality

\section{INTRODUCTION}

The debate on the ethics of alternative technologies is taking on a special place in the scientific literature today. It is also making its way in the general public press with a surprising presence; with the interest that many citizens have shown in it over the last few months attesting to this. The same applies with the simple case of the autonomous car, which finds itself on the roads, but even more worrisome, are the autonomous weapons systems or other devices involving the health or safety of goods and people. The political world is itself being overwhelmed with thoughts about the ethics of these technologies, and this is particularly the case regarding artificial intelligence. As usual, the thought spans from the confrontation of established social norms and the new uses of the technologies that are invading the socioeconomic, commercial, medical, defense fields. One of the first consequences is that the use of such technologies tends to be codified. These technologies are increasingly autonomous, and we can clearly see discussions emerging about the problems that would be caused by future machines that extend, enhance, or even purely and simply replace humans, with means that are caught up in a dizzying acceleration movement. Such is the case of transhumanist technologies, whose consequences of use and diffusion has, for the time being, remained curiously little debated on. 
The hopes and fears attached to the use of neo-technologies result in moral questions that are no longer simple theoretical questions. Hitherto confined to a few experts, many questions are now becoming central, concerning each individual's life, whether he or she is a potential user, a user, an owner... Some of these technologies invoke the concept of hybridity between humans and artificial, or include these humans in socio-technical systems, large parts of which escape simple understanding. Each person is then confronted with the difficult equation of balancing knowledge, mastery, or submission to technologies that he or she endures with varying degrees of satisfaction, confidence, mistrust, and anguish.

The causal chain in matters of liability is still far from being established. We are thus witnessing this same type of thoughts among legal specialists and insurers. In the digital world, the issue of shared responsibility, from the design to the marketing and use of systems; of consumer and user protection; of advertising; of the collection and use of personal data, is at the forefront. However, few studies have yet to address the case of cyclist accidents augmented by artificial systems (e.g., being run over by a car without a driver, or even without a person on board who can be aware of the accident. Similarly, the case of a worker trapped in his exoskeleton confronted with an autonomous or remotely operated collaborative robot is not studied. Also, the case of a protester who is manhandled by an autonomous law enforcement device, or that of a citizen injured or possibly killed by a public or private security robot will probably need to be examined. It will also be necessary to decide on the desire to control a standardized pedagogy entrusted to non-human or hybridized systems; including the acceptance of the risk of poorly instructed learner, of the poorly rehabilitated injured person or of the person whose autonomous prosthesis would escape the control of its defective or ill-informed carrier.

On an economic standpoint, the race for better performance and productivity gains in factory 4.0 opens the way to enhanced man. He is probably a profitable project; poorly paid, easy to control, easily replaceable, its training being simply contingent on the upgrade of his software. More efficient, more robust, it is certainly more adapted to the development plan of some companies that openly engage in the great sectors of the transhumanist socio-economic evolutions.

In the personal level, things are also confusing. We already know the refusal, the fear, or the desire of some for transformations, to benefit from artificial enhancements, depending on whether they are substitutive, therapeutic, comfort or performance.

If the collaboration, or even sometimes the functional fusion between man and machine is already here, it has its fierce opponents as well as its followers and supporters or its economic and ideological promoters. Bioethical and regulatory laws are often obsolete across borders. Such is the case of genome modification, of the instrumented control of health, of one's descendants and of one's life, or of the technologized control of death. A majority of scientists still claim that these are futuristic hypotheses, while others think that neotechnologies (neotechnologies) are already at hand in humanity and its evolution. For them, their generalization only depends on cultural elements and ethical reluctance to overcome, avoid, master or control.

The position that is defended in this article is based on the following observations. The delay of moral and ethical thinking on technologies is considerable, and the delay on "human enhancement" is dizzying. Although the logic of disciplinary silos logically handicaps the closing of this lag, we nevertheless regret the absence of an objective approach to this field of questioning, as well as the absence of analytical tools. These technologies are indeed particular in the sense that they only exist today at the project stages, or even as prototypes, for the most advanced of them. Ethical positions are therefore based on a form of confusion between an often spontaneous, sometimes fantasized reasoning, and the probable perspective of a scientific future that is invading humanity. The absence of an inventory of possibilities does not allow anticipation and sectorizes the analysis according to specific applicative domains, without taking into consideration the globality of objects and uses.

\section{THE TECHNOLOGICAL INCREASE OF HUMANS AND ENHANCED HUMANS}

"Human enhancement" corresponds, in its modern version, to a scientific and technological field that developed at the beginning of the century. It was formalized, at the request of the National Science 
Foundation and the American Department of Commerce, thanks to the NBIC report, which deals with convergent technologies that allow for the improvement of human performance. Above all, it represents a call from several scientists on the awareness of the need for an interdisciplinary, integrative, and synergistic approach, associating four major emerging fields of technology. Its goal is to allow the unification of a "convergent" science at the service of human performance, regardless of whether it is physical or mental, for health, quality of life, economy, and security. The approach is both scientific, economic, and strategic, and has mobilized the major state departments of the USA towards neo-technologies.

\section{FIGURE 1 \\ QUADRANGLE OF NBIC TETRAHEDRON}

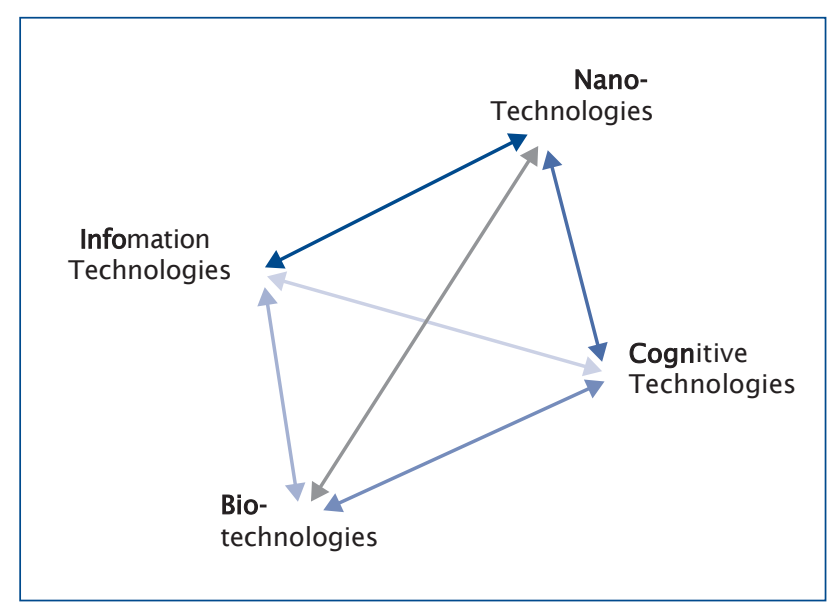

(Inspired by Rocco and Bainbridge, 2003)

Europe subsequently, mobilized a group of experts from the European Commission, which issued the Cteks report. It redefined the notion of "new technologies" by focusing on the development and societal demands and needs of European citizens. It determines a list of present and future neo-technologies that can meet these needs in a scientific and technological manner.

The main characteristic of these neo-technologies, or so-called "convergent" technologies, is their speed of development. It can be examined in terms of scientific and technical progress, but above all in terms of their deployment and use. It is from these two dimensions that a kind of gap arises between the complexity of their understanding and control, and the cognitive skills that humans can mobilize to use, understand, and control them. These neo-technologies certainly motivate ambitions, but above all fears, and resistance. The ethical positions of citizens who are increasingly faced with technological realities and their omnipresence in a world of constraints, raise the problem of social and individual acceptability in a globalized world. This article proposes a method of inventory and allows for the identification of different ethical positions mobilized in the face of neo-technologies.

\section{CONVERGING TECHNOLOGIES AND NEW INTERDISCIPLINARITY}

Neo-technologies come from the fields of application of four scientific sectors which are themselves multidisciplinary. Each one supports its field of expertise on disjointed fields of competence whose scientists engage in a transversal collaboration. These broad sectors are referred to as NBIC (Figure 1).

Nanotechnologies $[\mathrm{N}]$ are technologies for manipulating the physical world on a nanoscale and are organized into two fields. Bottom-up nanotechnologies are in the field of physics or chemistry and aim at the production and use of new nanostructured or nanocomposite materials. Top-down nanotechnologies aim at the ultimate miniaturization of electronic components for ever smaller micromechanical systems. Biotechnologies [B] focus on modifying living organisms, with new bio-active molecules, with targeted 
effects, or by directly attacking molecular synthesis by modifying the genome, for example using CRISPRtype techniques. These biotechnologies have different fields of application with different names varying from one author to another: red biotechnologies for medical purposes or human or animal health, green biotechnologies for agriculture and the environment, white biotechnologies for industry and energy. Information technologies [I] correspond to the fields of computer science and electronics, particularly with developments such as AI, big data, and flexible electronics. We can thus globally distinguish two domains: that of software and that of supports, materials, and networks. Cognitive technologies [C], or cognition technologies, are those that focus on the performance of human thought. It aims at enhancing, improving, and mastering the problems of interface in man-machine communication, those of management or sharing of knowledge between humans, with a view to increasing the performance or reliability of perception, cognition, decision or action. Finally, these four domains have appropriated a fifth convergent theme that concerns sustainability, the environment, and the future of humanity: "sustainable and economic development" [E] or [S]. This last point remains nevertheless very inspired by movements of technologist thoughts, including exploiting non-traditional environments (marine or spatial, or even for some hybrids between biology and artificial).

A distinction must be made between these technological fields that have been studied or developed, often at an excellent level in OECD countries, and their convergence around concrete projects, demonstrators, or products. Neo-technological convergence has the explicit aim of increasing human performance. For the time being, it is often confined to multidisciplinarity or two-by-two interdisciplinarity $(2 \times 2)$. We can thus meet bioinformatics productions [B $+\mathrm{I}]$, learning or care technologies in virtual reality $[\mathrm{I}+\mathrm{C}]$, bio-inspired prostheses with implanted controls $[\mathrm{B}+\mathrm{C}]$, deep IoT sensors $[\mathrm{N}+\mathrm{B}]$, large displays allowing shared representations $[\mathrm{I}+\mathrm{C}]$, etc. Nevertheless, it is more of a specialty that opens up for uses in another, rather than real convergences such as future pharmacological nano-vectors, bio-implantable nanomaterials, nanobots or informational dust, neuronal stimulators

in the healthy subject, industrial or home robotic companions, CRISPR-Cas9 for health, pleasure or enhancement, production of hybrids for agriculture and other genetically modified plant or animal organisms for food or disease vector control, etc. If $2 \times 2$ convergence is still rare, then $3 \times 3$ convergence is exceptional. As for the global $4 \times 4$ (or even $5 \times 5$ ) convergence called forth by some, it is still, some twenty years ahead of the NBIC report, in the order of the hypothesis, beholding the scientific dream.

It is in this convergence that many fears are based. While the disciplinary sectors already portray fantasies and mistrust from the citizens who are increasingly critical of science, in an era of dissemination of untruths and of questioning of evidence and established theories, the emerging contributions suffer even more from the blows of neo-ludittes, degenerates and religious fanatics or conspiracy theorists. As far as the NBIC convergence is concerned, the situation is all the more critical as we know little about a future, which is difficult to predict.

\section{HUMAN ENHANCEMENT AND THE TRIPLE FEAR OF OVERTAKING}

Speaking of convergence, it is the field of human enhancement and augmented/enhanced man that seems to pose the most problems, purveyors of all fantasies, inspired by science fiction or military paranoia and followers of the transformation of their own body. This field is to be examined according to several disruptive axes. The fears are multiple and have their own characteristics; they are nevertheless part of the great cultural currents.

It is interesting to note that disruption is a principle of industrial innovation. What is disruptive is that which breaks the prediction, that which is essentially unpredictable, while at the same time being part of an idea of progress or a change of paradigm. For the industrialist, the fear is therefore about "what could happen" and which cannot be quantified. Certainty is foreign to it, sometimes one even refers to irrationality. This is also the domain of serendipity or misuse, which are often at the origin of dual technologies. These are developed in and for an applicative sector, conforming to certain moral practices, and after some time find themselves as leading techniques in a field that is disjointed both in terms of utility and ethics. A famous example is that of ultrasound, discovered in biology, then developed for the hunting 
of submarines in the First World War, it was then used in industry before meeting a huge success in medicine. Today, they appear on airfields to scare birds, or to measure speed on roads.

Each of these applications raises moral questions, from anti-militarist positions to those of a medically assisted human selection, including the disturbance of cetaceans or that of teenagers who are more sensitive to ultrasound than elderly people who seek calm.

In the same way, we can cite several NBIC examples. The exoskeleton dreamed of by the military now allows orthopedic rehabilitation, mobility of paraplegics or ensures the balance of elderly who fall. The 3D immersion of video games relieves burn victims, treats phobic, teaches anatomy, or allows for more precise surgical interventions. It facilitates collaborative design and operational maintenance in the industry of the future. Drones serve for both security and air operations, forest, and border surveillance. Unfortunately, they have also become terrorist weapons. Generic engineering opens up applications to cancer treatment as well as eugenics, and nanotechnologies offer the prospect of future medical successes as well as major infringements on individual freedoms.

The duality is thus accompanied by a multiplicity of moral conceptions. And every technology is dual, in the sense that it can be used to "do good" as well as to "do evil", and these definitions are highly cultural. Hence the need, beyond classifying technologies and risks, to determine the different fears, limits, or advantages for some, which are not for others.

\section{THE EMERGENCE OF NEW FEARS}

The acceleration of NBICs is at the origin of the emergences whose applications or uses are often uncontrolled. Today, it is impossible to take stock of them, and each month sees a new development, for better or for worse.

Civilian mini drones guided by enhanced reality headsets have proven to be a threat to privacy, air safety or even global security. They are becoming a major problem for law enforcement or aviation security. In recent conflicts, soldiers have been victims of such drones equipped with grenades. Police and military personnel are already confronted with the psychological difficulty of physically neutralizing civilians, or even children, suspected of flying malicious drones. Smartphones with geolocation record movements and conversations, and the connected speakers of major Internet users listen to the privacy of their subjects. The problems of confidentiality and invasion of privacy are limitless, with the commoditization of personal data, e-commercial control of social networks, or control of workers by unscrupulous employers. Some northern countries already offer the "chipping" of individuals. It was used for veterinary identifications, it is now a means of payment, subscription access, or specific opening of controlled doors. These chips can be easily programmed from a smartphone and put in communication with external or internal electronic devices. The CRISPR genetic engineering kits or "Genetic Engineering Home Lab Kit" allow with a centrifuge and some products and materials easily accessible on the Internet to practice personal biohacking. The methods are simple, and complete guides are also available on the darknet.

Some intellectual movements, very present on social networks, believe that the future is to allow each person to electrically equip themselves or to transform their own genetic heritage according to the principle of "free disposal of their body". Such genome manipulation controlled by individuals could be institutionalized by rogue states or terrorist organizations. This CRISPR danger is recognized by scientists as exponential and reported since 2016 as one of the global threats ${ }^{1}$ of the "weapons of mass destruction" type, ranked just after the nuclear and chemical weapons danger ${ }^{2}$. On the other hand, scientists are promoting a positive vision of these genetic methods as a driving force for human engineering, and international conferences are being organized for this, such as the one devoted to "genome editing \& engineering".

Faced with such challenges and the differences in the representations of decision-makers, politicians, as well as scientists and practitioners, certain movements are emerging in a kind of confusion between illdefined notions of "fear of technology", "resistance to change", "cataclysmic threats" "transhumanism", "health morality", etc. The return of neo-Luddite (Figure 2) has led some people to take actions that now go as far as invading lecture halls, preventing people from speaking, or preventing them from working in 
laboratories, which is probably only one step away from attacking people. At the same time, there is a great demand for protection, in often contradictory public debates. This type of concern is moreover marked in France by the creation, in 2015, of a National Advisory Council for Biosafety (CNCB) with the mission of reflecting on "possible misappropriations of life technologies". The recent revision of the bioethics laws in 2018 addresses, in particular with regard to personalized medicine, the use of the genome and that of nanotechnologies, "with the risks of monitoring and control of a citizen's deeds and gestures via implants."

In this completely chaotic landscape, some are calling for international regulations and moratoria for the control and regulation of neo-technologies, especially in AI, robotics, brain-computer interface, and implantation techniques. The banning of killer robots or armed autonomous drones, which are extensions of human action, is one example. Specialists are reflecting on the sharing of power between man and machine, and some go so far as to draft proposals to ensure that algorithms and AI remain controllable, so that man does not lose control, as the French National Commission for Information Technology and Freedom (CNIL) has just proposed. The particular aspect of "autonomous lethal weapon systems" (SALA), according to a recent statement by the Minister of the Armed Forces, sets France's policy away from this practice. However, there is a need for reflection on the legal and ethical principles that could govern these new capabilities, particularly in terms of defense, in the event of an attack from such devices. This is one of the challenges of the new integrated space defense system designed to protect European satellites.

Nevertheless, we note that many converging technologies are beyond control, or even beyond consideration, and we are increasingly witnessing a democratization of methods with easy access to less and less expensive tools. The advent of 3D printers suffers in this regard from a thought of its prospects, including the printing of living matter. While everyone can already use a "Cobot", a companion robot or an artificial life partner, having chips inserted in them at an "implant party", modifying one's DNA with "garage biotech" kits, or the GAFAs are at the helm of convergence, with media power, power over public opinion as well as budgets immensely superior to those of the majority of states.

\section{THE MORALS OF AGAR}

The analysis of ethical standpoints vis-à-vis NBIC neo-technologies can be analyzed according to four bases that we owe to Nicholas Agar. We can thus rationally evaluate the different moral standpoints that are generated by the confrontation with these new questions. We can then theorize a sort of scale going from the conservative to the post-humanist. The latter, follower of an openly liberal movement, sees no substantive difference between a genetic kit and a Lego box. This liberalism is above all libertarian, promoting the idea that no authority should hinder the freedom of the individual from making a choice concerning his own future, his body, his mind, and their combined evolution towards a better future. Agar therefore studied the way in which the moral standpoint of the individual will be shaped once confronted with the new and potentially disturbing question of eugenics, as it is envisaged thanks to NBICs. He rejects a priori any idea according to which man would have a moral duty to refuse, or even not to use an improving technology. 


\section{FIGURE 2}

\section{CIRCLE OF MORAL STANDPOINTS}

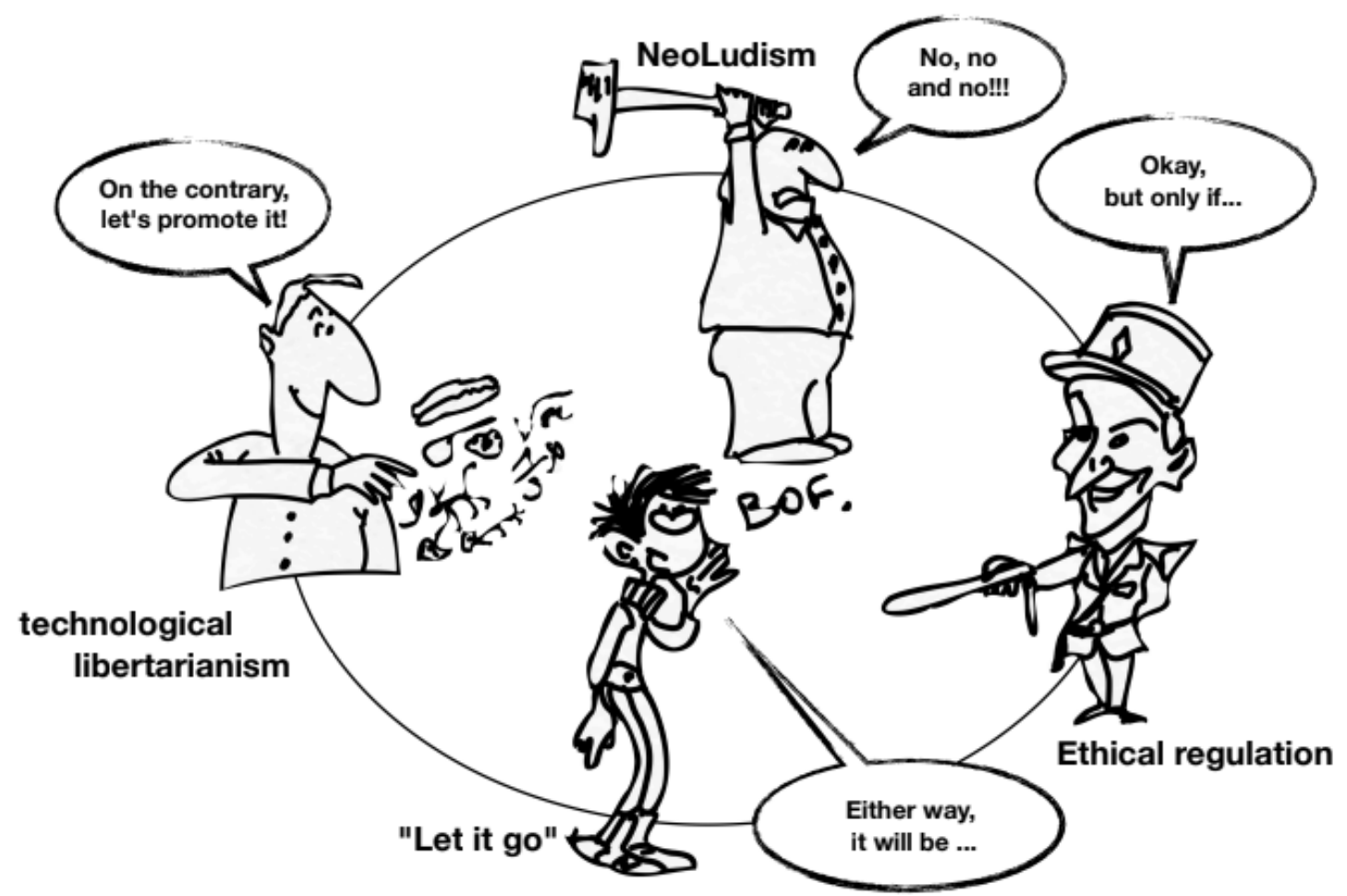

According to Claverie and Le Guyader

From the referential gaps of the individuals described by the author, we can imagine a quaternary classification of ethical standpoints. A first approach, "moral for health", the most frequent, tends to promote neo-technological approaches for the health and well-being of individuals who are ill or, in terms of risks and prevention, likely to develop pathologies, and even to mitigate aging. This approach obviously includes the perpetual concern to push back the frontiers of death, to push it back, or even, to eliminate it. A second approach, "morality for nature", tends on their part, and in a distinct way from the first one, to value the initiatives for the safeguard of nature, of the ecosystems, and of the planet, but also of the space, which are thought of as the common goods of humanity. A third position, "humanistic morality", consists in privileging the future of humanity and the cultural happiness of future populations through the acquisition and enrichment of people and communities. A final position, which can be called "libertarian morality", promotes the individual freedom to determine one's own future. Each of these positions allows its proponent to construct a standpoint whose arguments enable him/her to oust the others.

\section{QUATERNARY CLASSIFICATION OF ETHICAL STANDPOINTS}

If research on neo-technologies is globally impacted by moral problems, we cannot minimize the difficulty of their definition, as well as the variability of what it covers according to culture, at the global level of the countries and the policies in place, but also at the level of individuals with age and personality differences.

A first position, inspired by the counter-technological culture, corresponds to "neo-Luddism". This current tends to reject progress and its followers try to organize resistance against it, as it is conceived as a threat. It promotes reflections and even concrete actions against technological development. Here, we obviously find the "technocritical" movements and the "enemies of the machine". The common position of such movements (state 1 of figure 2) is that of the precautionary principle, of the fear of the risk involved 
in the disruption of established things and of the questioning of personal or societal achievements, or of the current organization of biological, cognitive, cultural life, etc. Progress is conceived as alienating and must be interrupted to promote alternative ways of life, most often inspired by the wisdoms of the past.

More nuanced, the followers of regulation (state 2) accept technological progress, but in a restrictive and controlled manner. Although this standpoint is akin to a form of resistance to technology, it admits the exceedance of the targets, considering that they must be circumscribed to precise fields of application for which the exception is recognized as moral, and within strictly agreed limits.

An alternative position is that of "laisser faire", a kind of disinterest or negation of the problem, and delegating to others of the choices to be made in this matter. Such can find his/her motivation in a lack of interest for the technological thing and for his/her future, or in an awareness of the cognitive or cultural overcoming, confining the person in a kind of melancholy or neutrality that can be, moreover, a motivated choice or even an ideological position in its own right (state 3).

A last standpoint makes it possible to differentiate the supporters of an incentive liberalism, directed towards the production of value (state 4) or directly partisans of a transhumanist evolution. Neotechnological systems and practices are then conceived as being capable of self-regulating in a form of globalized competition (bottom-up) or of strategic economic or political organization (top-down). This competition can be considered between States, between companies (such as GAFA, or other industrial groups, including small and medium-sized companies), and even between or with countries. It is amusing to note a closing of the circle of moral standpoint with a pronounced tendency of wanting to prevent any competitive method or method that one does not control for one's own benefit.

TABLE 1

\section{EXAMPLES OF ETHICAL TENDENCIES IN A CLASSIFICATION INSPIRED BY AGAR'S MORALS FOR THE FOUR POSITIONS}

\begin{tabular}{lllll}
\hline $\begin{array}{l}\text { Morals } \longrightarrow \\
\text { Standpoint } \downarrow\end{array}$ & Health & Nature & Culture & Liberal \\
\hline $\begin{array}{l}\text { Neo-luddism } \\
\text { Ethical regulation }\end{array}$ & Bioethics & $\begin{array}{l}\text { Total partial or specific refusal based on a moral field } \\
\text { Protection of the environment (geology and biology) and } \\
\text { space }\end{array}$ & $\begin{array}{l}\text { Education and } \\
\text { culture for future } \\
\text { generations }\end{array}$ & $\begin{array}{l}\text { Economy and } \\
\text { value of } \\
\text { production }\end{array}$ \\
$\begin{array}{l}\text { Let it be (laissez Faire) } \\
\text { Incentive }\end{array}$ & $\begin{array}{l}\text { Health } \\
\text { economics }\end{array}$ & $\begin{array}{l}\text { Global or partial lack of interest in one or more fields } \\
\text { agriculture, and } \\
\text { space }\end{array}$ & $\begin{array}{l}\text { Production of } \\
\text { culture and } \\
\text { services }\end{array}$ & $\begin{array}{l}\text { Production of } \\
\text { value }\end{array}$ \\
\hline
\end{tabular}

According to Claverie and Le Guyader

We can then, in these four cases, and drawing inspiration from Agar's classification, propose a differentiation of each of them according to the four proposed fields of application, which constitute four different "compartments of ethics": for health, for nature, for the assets and culture, global and libertarian.

In the perspective of studying such ethical issues, preferences or tolerances of individuals or groups, it seems relevant to have descriptive evaluation tools. The factorial plan (Table 1) thus provides a "clinical" description of each of the ethical positions of individuals according to the proposed taxonomy and that inspired by Agar.

The two independent description factors make it possible to position each person according to his or her convictions, ranging from neo-luddite refusal to the incentive to do, through regulatory regulation or the laisser-faire, for each of the specific fields of application: for health, for nature, for human promotion 
and the circumstances of its cultural evolution, or for the production value. Such a descriptive grid simply makes it possible to precisely describe the ethical positions adopted by individuals and groups, as well as to allow for the analysis of temporal transitions from one position to another. It makes it possible to position the opinions and convictions of individuals, and to shed light on the varieties, which are often incompatible with each other.

\section{CONCLUSION}

Addressing the question of ethics in a field as varied as that of neo-technologies has multiple dimensions. Indeed, we are struck by the differences between the standpoints that certain people can mobilize according to major personal or collective tendencies, and this according to the fields concerned by these technologies. The observation of adopted standpoints, as the case may be, addresses dimensions of miscommunication, or even conflicts. The refusal of technologies is clearly incompatible with the incitement to develop these technologies in the promotion of a form of progress that sometimes crushes individuals, and soon, societies. Detachment is also inconsistent with the desire for regulation, prohibition, or strong constraints.

However, these adopted standpoints seem variable within the same person, based on thematic adjustments, and if this or that person can be favorable to the development of one of them in the health field, for example, he or she can very well refuse its use just for the creation of value or because of its environmental consequences, and so on.

Beyond measurement and expectation, setting the limits of human enhancement technologies opens up several problem areas that are illuminated by a description such as the one proposed in this article. It allows us to position the stakes and describe the sectorial and thematic consequences. It points to the major questions that specialists ask themselves according to their disciplinary sector, regardless of whether they are scientists, practitioners, politicians, jurists, or simple informed users, who are waiting for certain technological developments. The questions are all the more difficult as they concern NBIC technologies whose application consequences are far from trivial, and some aspects of which are only discovered as they emerge.

For example, are we going to end up with technologies that are accessible to everyone, but which are forbidden to certain people who are willing to use them? What position should we adopt for people in a weak situation or under guardianship? What attitude should be adopted towards individuals who are already modified: are we going to forbid them certain accesses, certain jobs, certain statuses, or certain establishments, in a form of new apartheid and partition of the world between transhumanists and neoluddites, or between those who have access to technology and those whose resource conditions forbid them? What about the prospects for children, between those who authorize certain techniques and those who refuse them? Can we envisage imposing or forbidding transformations for reasons of public health, security or cultural, professional, or military performance, as we seem to want to do today in environmental matters? What about the sacrosanct precautionary principle?

Another category of problems often neglected is that of time constants. What are the durations or periods of application concerned? The question of resilience to technical obsolescence and software upgrades, that of security breaches of digital components or biological modifications, that of pathophysiological reactions and new induced pathologies, regardless of whether it be acute or chronic, from interference and other alterations due to electromagnetic sensitivities, that of the protection of networks and access to energy sources, which vary according to the positions and the fields concerned. The problem of affecting the programs necessary for the functioning of elements, assemblies and entire systems is also linked to the problem of the biological modification of bodies or minds. Can the voluntary or accidental alteration by external or internal means, whether by radiation or by software intrusion, of the functioning of implanted components be considered as an attack on the person, as an assault? Can the altering consequence be considered as a handicap? Does this one need to be overcome if it would take out a new function, while making others functional again? Can an unexpected or inaccessible emerging function be considered as natural? Is the benefit or deficit monetizable, and therefore taxable? 
Another debate is that of societal issues in a globalized competition where the time for ethical or regulatory reflection is often seen as that of technological delay. This is the case in Western Europe compared to certain countries that are already openly developing convergent enhancement technologies. What is the attitude towards certain companies or certain groups with a commercial vocation, with ambitions of superiority or destruction? Europe has, for reasons of its own, missed a lot of opportunities: in cybernetics; implantable electronics; computer manufacturing; the Internet of Things; collaborative, and cognitive robotics. Today, she (Europe) is trying to maintain her position in nanotechnology, biotechnology, AI, and the Internet of Things with 5G. Perhaps she should ask herself about the future of their convergence. For the neo-technologies of enhancement and substitution, is it a question of maintaining a form of independence and no longer being subject to the products prepared by big trusts and which would be imposed on it? Should we limit, or even prohibit, as proposed by some politicians and jurists, scientists, and philosophers, or should we go beyond these borders to at least master, if not act and control, or even create value? This can be done by differentiating the stakes, and by reasonably and specifically questioning each vector of resistances, hopes and prohibitions, in a space which we must not forget is globalized, and where each culture can probably develop its specificities while remaining in the movement of the neotechnological competitiveness.

\section{ACKNOWLEDGEMENT}

Translated \& edited by American Publishing Services (https://americanpublishingservices.com/).

\section{ENDNOTES}

1. https://www.dni.gov/files/documents/SASC_Unclassified_2016_ATA_SFR_FINAL.pdf (assessed on June 6, 2019).

2. https://www.scribd.com/document/337602380/Lettre-des-conseillers-scientifiques-de-Barack-Obama-surCRISPR-Cas9 (accessed on June 6, 2019).

\section{REFERENCES}

Abudayyeh, O.O. (2017). RNA targeting with CRISPR-Cas13. Nature, 550, 280-4.

Agar, N. (2004). Liberal Eugenics: In Defence of Human Enhancement. Hobo- ken (NJ, USA): WileyBlackwell.

Bersini, H. (2017). Big Brother is driving you. Bruxelles (Belgique): Académie Royale de Belgique.

Claverie, B. (2005). Cognitique: Science et pratique des relations à la machine à penser. Paris:

L'Harmattan.

Claverie, B. (2010). L'Homme augmenté: Néotechnologies pour un dépassement du corps et de la pensée. Paris: L'Harmattan.

Claverie, B. (2010). Pluri-, Inter-, Transdisciplinarité, ou le réel décomposé en réseaux de savoir. Revue Internationale de Projectique, 4, 5-28.

Claverie, B. (2021). Ethical standpoint in relation to neo-technologies: Classification plan, miscommunication, and perspectives. L'Information Psychiatrique, 97(2), 147-155

Claverie, B., \& Le Guyader, H. (2018). Approches éthiques des néotechnologies d'augmentation de l'humain. Ingénierie Cognitique ISTE, 2. doi:10.21494/ISTE.OP.2018.0272

CNIL. (2017). Comment permettre à l'homme de garder la main? Les enjeux éthiques des algorithmes et de l'intelligence artificielle: Mission de réflexion éthique confiée par le Loi pour une république numérique. Paris (France): Édition CNIL.

Faillet, C. (2016). L'art de la guerre digitale: Survivre et dominer à l'ère du numérique. Paris: Dunod.

Goodall, N.J. (2016). Can You Program Ethics Into a Self-Driving Car? When self-driving cars kill, it's the code (and the) that will be put on trial. IEEE Spectrum. 
Guarnotta, V. (2015). Rapport sur les dispositifs médicaux implantables. Proceedings of the EDiversification Santé. Toulouse: Aerospace Valley- DIRECCTE Midi-Pyrénées.

Jarrige, F. (2016). Technocritiques. In Du refus des machines à la contestation des technosciences. Paris: La Découverte.

Jones, S.E. (2006). Against Technology: From the Luddites to Neo-luddism. Oxford (UK): Routledge.

Ledford, H. (2016). CRISPR: Gene editing is just the beginning: The real power of the biological tool lies in exploring how genomes work. Nature, 531, 56-159.

Nordmann, A. (Ed.). (2004). And the High Level Expert Group Foresighting the New Technology Wave. Converging Technologies - Shaping the Future of European Societies. Bruxelles (Belgique): European Commission, Office for Official Publications of the European Communities.

Roco, M.C., \& Bainbridge, W.C. (Eds.). (2003). Converging Technologies for Improving Human Performance: Nanotechnology, Biotechnology, Information technology and Cognitive science. National Science Fundation / Department Of Commerce sponsored report. Dordrecht (The Netherlands): Kluwer Academic Publishers (Springer).

Tribot de la Spière, L., \& Cothier, P. (2017). La défense écartelée. Paris (France): Editions Le Manuscrit. Villani, C. (Ed.). (2018). Donner un sens à l'intelligence artificielle, pour une styratégie nationale et européenne / Rapport au premier ministre. Paris (France): Aiforhumanity/Imprimerie nationale/Direction de l'information légale et administrative.

Warren, A., \& Hillas, A. (2017). Lethal Autonomous Weapons Systems, Adapting to the Future of Unmanned Warfare and Unaccountable Robots. Journal of International Affairs, 12, 71-85.

Wohlsen, M. (2011). Biopunk: M. Solving Biotech's Biggest Problems in Kitchens and Garages. NewYork (USA): Penguin. 